\title{
A Carbon Nanotube Modified Electrode for Determination of Caffeine by Differential Pulse Voltammetry
}

\author{
Biuck HABIBI ${ }^{1,{ }^{*}}$, Mehri ABAZARI ${ }^{1}$, Mohammad Hossien POURNAGHI-AZAR ${ }^{2}$ \\ ${ }^{1}$ Electroanalytical Chemistry Laboratory, Department of Chemistry, Faculty of Sciences, Azarbaijan University of Tarbiat Moallem, \\ Tabriz 53714-161, Iran \\ ${ }^{2}$ Center of Excellence of New Materials and Clean Chemistry, University of Tabriz, Tabriz 5166616471, Iran
}

\begin{abstract}
A simple and sensitive electrochemical detection of caffeine (CAF) using a single-walled carbon nanotubes on carbon-ceramic electrode (SWCNT/CCE) is reported. CAF was oxidized at the surface of the modified electrode to produce an anodic peak at $1.38 \mathrm{~V}$ versus the saturated calomel electrode in $0.01 \mathrm{~mol} / \mathrm{L}, \mathrm{pH} 1.7 \mathrm{H}_{2} \mathrm{SO}_{4}$ solution in cyclic voltammetry. The experimental parameters, namely, type of electrolyte, $\mathrm{pH}$ value, and amount of SWCNTs casted, were optimized. Using the optimum conditions, the anodic peak current in differential pulse voltammetry was linear with CAF concentration in the range of $2.5 \times 10^{-7}-1.0 \times 10^{-4} \mathrm{~mol} / \mathrm{L}$. The detection limit was $1.2 \times 10^{-7} \mathrm{~mol} / \mathrm{L}$ $(\mathrm{S} / \mathrm{N}=3)$. The modified electrode exhibited good stability and can be easily regenerated. The relative standard deviation of the peak current obtained for a $5.0 \times 10^{-5} \mathrm{~mol} / \mathrm{L}$ CAF solution was $3.0 \%$. The influence of some important biological compounds, namely, ascorbic acid, dopamine, and uric acid and addictive compounds like codeine, morphine, and acetaminophen on the CAF anodic peak current was examined. The method was successfully applied for the determination of CAF in some practical samples.
\end{abstract}

Key words: caffeine; electrocatalysis; electrochemical determination; single-walled carbon nanotube; carbon-ceramic electrode CLC number: O643 Document code: A

Received 22 June 2012. Accepted 26 July 2012.

*Corresponding author. Tel: +98-412-4327541; Fax: +98-412-4327541; E-mail: B.Habibi@azaruniv.edu

English edition available online at Elsevier ScienceDirect (http://www.sciencedirect.com/science/journal/18722067).

Caffeine $\left(\mathrm{C}_{8} \mathrm{H}_{10} \mathrm{~N}_{4} \mathrm{O}_{2}\right)$ is the common name for 1,3,7-trimethylxanthine (3,7-dihydro-1,3,7-trimethyl-1Hpurine-2,6-dione) $[1,2]$. Caffeine (CAF) is one of the most widely used drugs in the world and has many important pharmacological effects such as the stimulation of central nervous system, diuresis, and a positive effect on the cardiovascular system $[3,4]$. CAF is also used therapeutically in combination with ergotamine in the treatment of migraine and in combination with nonsteroidal anti-inflammatory drugs in analgesic formulations [5]. It is sometimes included in analgesic preparations because of its diuretic action [6]. Different methods have been developed for the determination of CAF [7-16]. Some of these methods, e.g., the chromatographic methods, are time consuming, expensive, and need complicated pre-concentration or multiple solvent extraction and trained technicians, but electrochemical methods are characterized by simplicity, high sensitivity, good stability, low cost instrumentation, and onsite monitoring [17]. In order to enhance the sensitivity and stability of the measurement, various modified electrodes have been developed and used in the electrochemical determination of CAF [1,18-28], but the electroanalysis of CAF has seldom been reported because the oxidation of CAF occurs at a very high positive potential.
Carbon nanotubes are molecular scale tubes of graphitic carbon with outstanding properties. They have attracted considerable attention for their extraordinary structural, mechanical, electrical, and electrochemical properties [29]. Their unique properties have led to applications in many fields such as electronics, medicine, aerospace industry, etc., which has also prompted the need for analytical methods to characterize and control the quality of CNTs. The use of CNTs as analytical tools and the construction of nanodevices and nanosensors based on these materials are exciting areas of modern analytical science [30-32].

In the current work, an enhanced sensor based on single-walled carbon nanotubes casted on a carbon-ceramic electrode (SWCNT/CCE) was developed for the sensitive determination of CAF. The electrochemical behavior of CAF showed that the SWCNT/CCE exhibited obvious electrocatalytic activity for the oxidation of CAF because it greatly enhanced the oxidation peak current of CAF with respect to that from an unmodified CCE. The stability and electrocatalytic activity and electroanalytical applications of the SWCNT/CCE in electrooxidation and detection of CAF were evaluated by different electrochemical techniques. Finally, in order to demonstrate the catalytic use of this modified electrode for the electrooxidation of CAF in some 
practical samples, we examined it with the voltammetric determination of CAF in tea, cola, and mineral water samples.

\section{Experimental}

\subsection{Chemicals}

The SWCNT was manufactured by CNI (USA). Methyltrimethoxysilane (MTMOS), caffeine, $\mathrm{H}_{2} \mathrm{SO}_{4}$, and other chemicals were purchased from Merck or Fluka and used without further purification. Doubly distilled water was used in the experiments. The $\mathrm{pH}$ of the solutions was adjusted with $0.1 \mathrm{~mol} / \mathrm{L} \mathrm{H}_{2} \mathrm{SO}_{4}$ and $\mathrm{NaOH}$.

\subsection{Apparatus}

The electrochemical experiments were carried out using a potentiostat/galvanostat (AUTOLAB PGSTAT-100) equipped with a USB interface and driven by a GPES 4.9 electrochemical software package (Eco Chemie, The Netherlands), a three-electrode system and a personal computer for data storage and processing. The three-electrode cell system employed for the electrochemical studies composed of a saturated calomel electrode (SCE) as the reference electrode, a platinum wire as the auxiliary electrode, and the SWCNT modified CCE (geometric surface area of 0.119 $\mathrm{cm}^{2}$ ) as the working electrode. A copper wire was inserted through the composite end of the working electrode to establish electrical contact. Scanning electron microscopy (SEM) was performed on a LEO 440i Oxford instrument.

\subsection{Preparation of bare and modified CCE}

The bare CCE was prepared according to the procedure described by Lev and coworkers $[33,34]$ by mixing $0.15 \mathrm{ml}$ MTMOS, $0.30 \mathrm{ml}$ methanol, and $10 \mu \mathrm{l}$ hydrochloric acid $(11 \mathrm{~mol} / \mathrm{L})$. This mixture was magnetically stirred for $2 \mathrm{~min}$, after which $0.3 \mathrm{~g}$ graphite powder was added and the resultant mixture was shaken for an additional $1 \mathrm{~min}$. A $5 \mathrm{~mm}$ length of Teflon tube (3-4 mm inner diameter) was filled with the sol-gel carbon mixture and dried under ambient conditions $\left(25^{\circ} \mathrm{C}\right)$. The dried CCE was first carefully polished with polishing paper, rinsed with doubly distilled water, and finally dried by air drying. To obtain a uniform layer of SWCNT on the CCE surface, $20 \mu \mathrm{l}$ of SWCNT $(\mathrm{DMF} /$ water $=1 / 3)$ solution $(0.4 \mathrm{mg} / \mathrm{ml})$ was placed on the surface of the CCE and dried in air.

\subsection{Preparation of practical samples}

CAF-free drinks (mineral waters) were spiked with 0.5 $\mathrm{mmol} / \mathrm{L}$ of CAF standard solution. The cola samples were appropriately diluted $(1: 10)$ with the electrolyte to bring them into the working range. In order to detect CAF in tea samples (Ahmad tea), a known amount (15.0 g) was weighted and dissolved in $250 \mathrm{ml}$ of double distilled water followed by boiling for $1 \mathrm{~h}$ on a hot plate with stirring. After allowing the residue to settle, the hot solution was filtered and then used for further experiments. A known amount (1 $\mathrm{ml}$ ) of this solution was added to $10 \mathrm{ml}$ electrolyte solution of $\mathrm{pH}=1.7$. The quantitative determination of CAF was achieved by measuring the oxidation peak current after background subtraction using differential pulse voltammetry (DPV).

\section{Results and discussion}

\subsection{Characterization of SWCNT/CCE}

Figure 1 is the SEM images of the SWCNT film on the CCE by SEM. Figure 1(a) shows the surface morphology of the bare CCE immediately after polishing with emery paper of grade 1500 . As seen in this image, the surface was dense, scaly, and had high porosity. Figure 1(b) shows the SEM image of the same electrode after SWCNT casting on the surface of the CCE. It can be seen that the SWCNT film was uniformly coated on the electrode surface and formed a
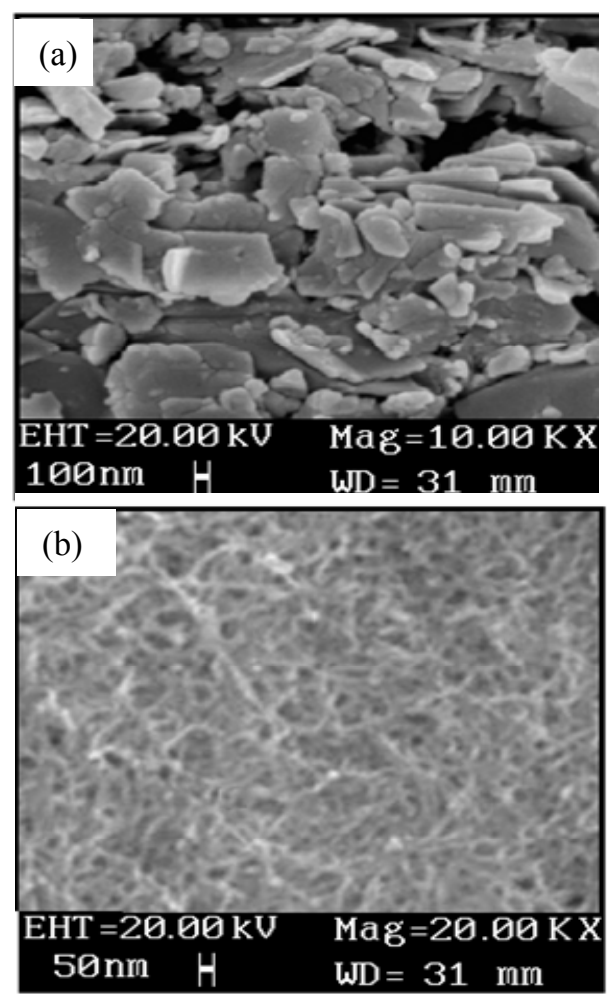

Fig. 1. SEM images of CCE surface immediately after polishing (a) and after SWCNT casting on it (b). 
spaghetti-like porous reticular formation. This surface morphology offered a much larger surface area than the apparent geometric area. To confirm this, the surface area of the modified electrode was estimated by cyclic voltammetry $(\mathrm{CV})$ using $\mathrm{Fe}(\mathrm{CN})_{6}{ }^{3-/ 4-}$ as probe ions. The surface area was calculated using the Randles-Sevcik equation [35]. The calculated electroactive surface areas for the SWCNT/CCE were $0.330 \pm 0.012 \mathrm{~cm}^{2}$, while the surface area for the bare $\mathrm{CCE}$ was $0.162 \pm 0.018 \mathrm{~cm}^{2}$ [36]. The significant increase in electroactive surface area suggested that the SWCNT/CCE is promising for electrochemical sensing. In addition, the stability and reproducibility of the electrochemical behavior of the modified electrode were also investigated by the $\mathrm{CV}$ of $\mathrm{Fe}(\mathrm{CN})_{6}{ }^{3-/ 4-}$ ions. The working stability of the modified electrode was verified by the electrochemical behavior of $\mathrm{Fe}(\mathrm{CN})_{6}{ }^{3-/ 4-}$ in successive sweeps of CVs. The peak currents with $5.0 \times 10^{-3} \mathrm{~mol} / \mathrm{L} \mathrm{Fe}(\mathrm{CN})_{6}{ }^{3-/ 4-}$ (anodic peak at $0.205 \mathrm{~V}$ and cathodic peak at $0.121 \mathrm{~V}$ vs SCE) from the SWCNT/CCE surface was almost $98 \%$ of its initial value after 200 cycles in the electrolyte solution and no significant decrease was observed when the electrolyte used for 200 repetitive cycles was replaced with a fresh solution (Fig. 2).

Also, the storage stability of the chemically modified electrode was very good. It was found to still have $98 \%$ of its initial activity when kept in air at room temperature for more than $20 \mathrm{~d}$, and only $4 \%$ loss was found when the modified electrode was immersed in $0.1 \mathrm{~mol} / \mathrm{L}$ sulfuric acid buffer solution for $48 \mathrm{~h}$. In order to study the reproducibility of the electrode preparation procedure, four independent CCEs were modified with SWCNTs. The cyclic voltammograms $(\mathrm{CVs})$ of these modified electrodes in $5.0 \times 10^{-3}$ $\mathrm{mol} / \mathrm{L} \mathrm{Fe}(\mathrm{CN})_{6}{ }^{3-/ 4-}$ solution were recorded. The relative standard deviation (RSD) of the measured cathodic peak currents was about $4 \%$ [36].

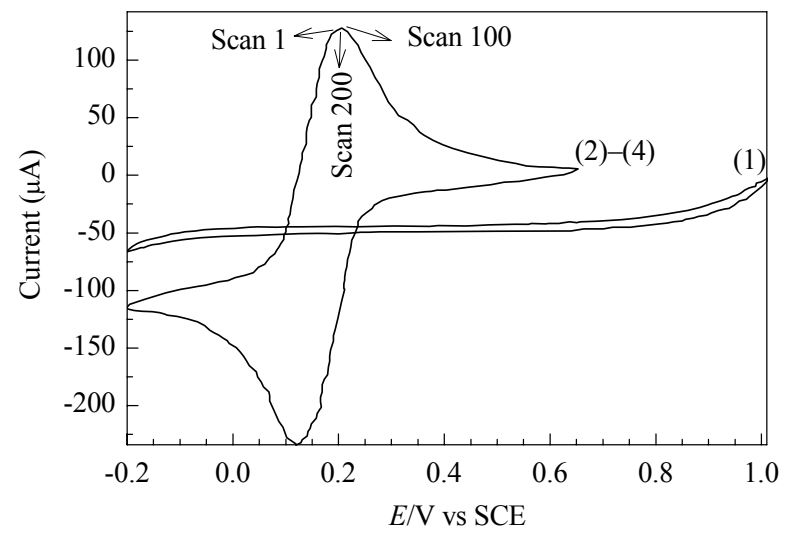

Fig. 2. CVs of the SWCNT/CCE in the absence (1) and presence of $5.0 \times 10^{-3} \mathrm{~mol} / \mathrm{L} \mathrm{Fe}(\mathrm{CN})_{6}^{3-/ 4-}$ in $0.1 \mathrm{~mol} / \mathrm{L} \mathrm{KCl}$ at potential range $-0.2-0.7 \mathrm{~V}$ for the $1^{\text {st }}(2), 100^{\text {th }}(3)$, and $200^{\text {th }}$ (4) cycles. Scan rate 50 $\mathrm{mV} / \mathrm{s}$, volume of SWCNT casted $20 \mu \mathrm{l}$.

\subsection{Electrochemical behavior of CAF on SWCNT/CCE}

Figure 3 shows the cyclic voltammetric responses of the bare CCE (curves 1 and 3) and the SWCNT/CCE (curves 2 and 4$)$ in the absence and presence of $3.0 \times 10^{-3} \mathrm{~mol} / \mathrm{L} \mathrm{CAF}$ in $0.01 \mathrm{~mol} / \mathrm{L}, \mathrm{pH} 1.7 \mathrm{H}_{2} \mathrm{SO}_{4}$ at a scan rate of $50 \mathrm{mV} / \mathrm{s}$. As previously reported [1,18-20, 24,25,37,38], this oxidation system is characterized by an anodic peak during the positive step and by the absence of any cathodic peak in the reverse scan, indicating that the oxidation is irreversible. As can be seen in Fig. 3(3), with the bare CCE, a small anodic current due to the weak oxidation of CAF was observed, and no cathodic peak was found, which indicated an irreversible heterogeneous charge transfer in this system. Under the same conditions, with the SWCNT/CCE a large anodic peak was observed (Fig. 3(4)).

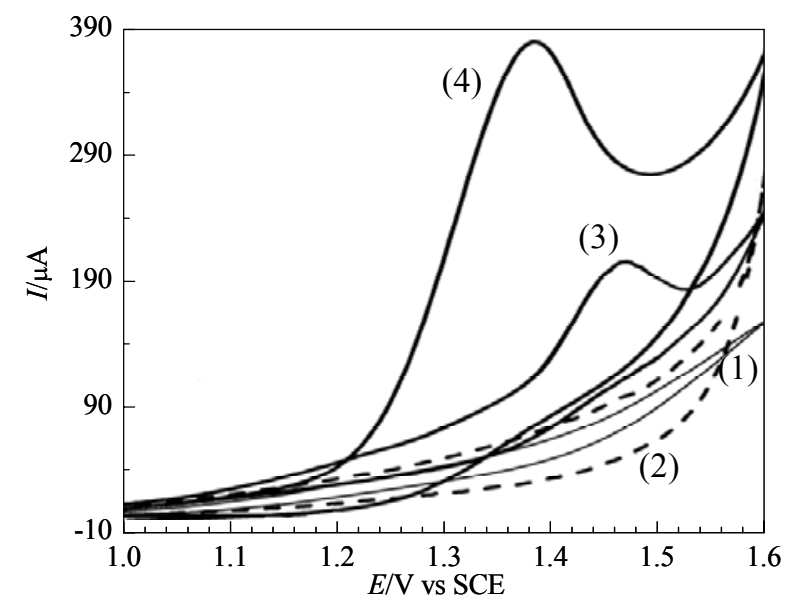

Fig. 3. CVs with the bare $\mathrm{CCE}$ (curves 1 and 3 ) and the SWCNT/CCE (curves 2 and 4) in $0.01 \mathrm{~mol} / \mathrm{L}, \mathrm{pH} 1.7 \mathrm{H}_{2} \mathrm{SO}_{4}$ in the absence and presence of $3.0 \times 10^{-3} \mathrm{~mol} / \mathrm{L} \mathrm{CAF}$. Scan rate $50 \mathrm{mV} / \mathrm{s}$, volume of SWCNT casted $20 \mu 1$.

The anodic peak potential for the oxidation of $\mathrm{CAF}$ at the modified CCE was $1.38 \mathrm{~V}$ versus the SCE, while that of CAF oxidation at the unmodified electrode was $1.48 \mathrm{~V}$. A considerable decrease in the overpotential $(100 \mathrm{mV})$ was observed with the modified electrode. Note also that the background current was slightly increased on the SWCNT/CCE due to the increase of the modified electrode surface area. The comparison of the CVs of CAF at the bare CCE and the SWCNT/CCE (curves 3 and 4) shows that CAF can be effectively oxidized at the SWCNT/CCE with a higher peak current, which demonstrated improved electron transfer kinetics and a promoted oxidation current. The improvement of the electron transfer kinetics and oxidation current from $\mathrm{CAF}$ at the SWCNT/CCE indicated that the SWCNTs had a good electrocatalytic effect on the electrooxidation of CAF. The high electrocatalytic activity for the SWCNT-modified electrode was attributed to the unique 
properties of the carbon nanotubes such as high specific surface area, subtle electronic properties, and appropriate pore structure. In particular, the SWCNTs present an interlinked highly mesoporous 3D structure with a larger electrochemically accessible surface area and easier charge transfer at the electrode/electrolyte interface.

Further experiments were performed to study the transport characteristics of CAF at SWCNT/CCE. The influence of the scan rate $(v)$ on the peak current of $3.0 \times 10^{-3} \mathrm{~mol} / \mathrm{L}$ CAF in $0.01 \mathrm{~mol} / \mathrm{L}, \mathrm{pH} 1.7 \mathrm{H}_{2} \mathrm{SO}_{4}$ solution at the SWCNT/CCE was investigated (Fig. 4). In the range 10 to $550 \mathrm{mV} / \mathrm{s}$, the peak current increased and the peak potential shifted to be more positive. There was a good linear relationship between the peak current and the square root of the scan rate $v$ (Fig. 4 inset (a)). The regression equation was $I_{\mathrm{pa}}$ $=0.51+80.33 v^{1 / 2}\left(R^{2}=0.997\right)$, suggesting that the electrode process was diffusion controlled. This result was in agreement with data previously reported [1,18,20,22].

We also used the above results to get information on the rate determining step. As can be seen in Fig. 4, when the scan rate was increased, the anodic peak potential of $\mathrm{CAF}$ electrooxidation at the SWCNT/CCE was positively shifted slightly. For an irreversible system, at high scan rates, $E_{\mathrm{pa}}$ and $\ln v$ should obey the equation [39,40]:

$$
\begin{aligned}
& E_{\mathrm{pa}}=E^{\prime}+R T /(1-\alpha) n_{\alpha} F \times\left(0.780+\ln \left(D_{\mathrm{CAF}}^{1 / 2} / K^{0}\right)+\right. \\
& \left.\ln \left((1-\alpha) n_{\alpha} F v / R T\right)^{1 / 2}\right)
\end{aligned}
$$

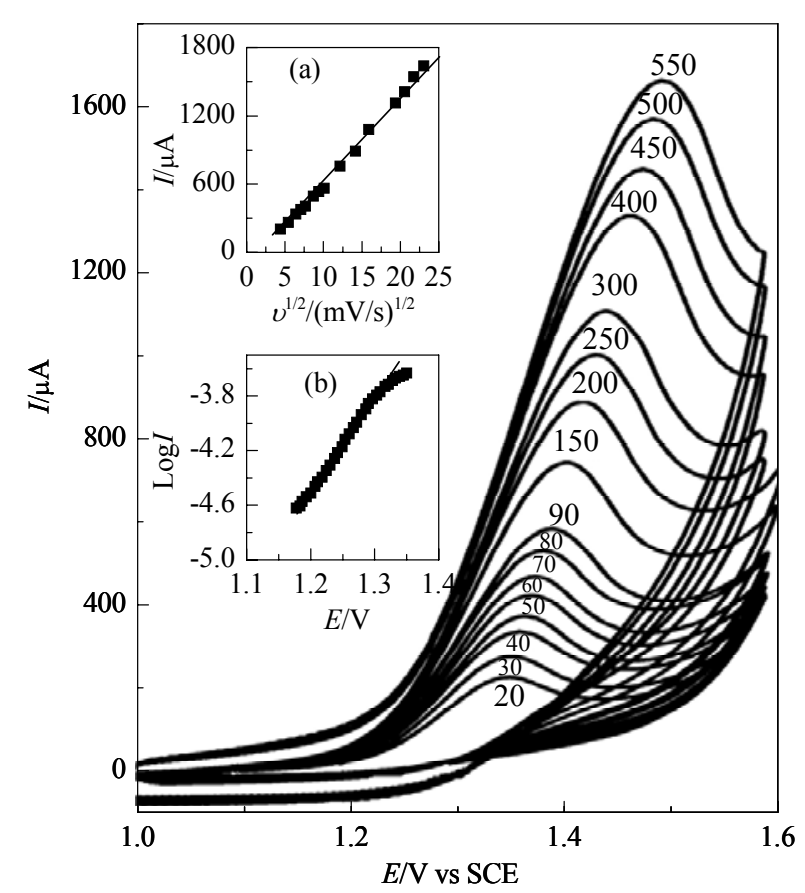

Fig. 4. $\mathrm{CVs}$ for electrooxidation of $3.0 \times 10^{-3} \mathrm{~mol} / \mathrm{L} \mathrm{CAF}$ in $0.01 \mathrm{~mol} / \mathrm{L} \mathrm{H}_{2} \mathrm{SO}_{4}, \mathrm{pH} 1.7$ solution at the SWCNT/CCE at various scan rates. Plots of peak currents vs square root of scan rate $\left(v^{1 / 2}\right)$ (inset (a)). Tafel plot for electrooxidation of CAF under the same condition with a scan rate of $10 \mathrm{mV} / \mathrm{s}$ (inset (b)). Volume of SWCNT casted $20 \mu 1$. where $\alpha$ is the transfer coefficient, $n_{\alpha}$ is the number of electrons transferred, $v$ is the potential scan rate, $F$ is the Faraday's constant, $R$ is the rate gas constant, $T$ is the absolute temperature, $K^{0}$ is the standard heterogeneous rate constant, and $D$ is the diffusion coefficient of CAF.

The analysis of the data and plot of the corresponding curve gave the peak potential $E_{\mathrm{pa}}=1.2734+0.0346 \ln v\left(E_{\mathrm{pa}}\right.$ in $V, v$ in $\left.V / s, R^{2}=0.998\right)$, which corresponded to $n_{\alpha}(1-\alpha)=$ 0.371 . Because the electron transfer coefficient, $\alpha$, for most electrode processes ranges from 0.7 to 0.3 [35], the electron transfer number $\left(n_{\alpha}\right)$ should be one [41] and hence $\alpha$ was estimated to be 0.63 , which was in good agreement with an earlier result [41]. On the other hand, to confirm these results, another method was used to get the same information on the rate determining step. For this purpose, a Tafel plot was used (Fig. 4 inset (b)) for the CAF at the surface of SWCNT/CCE using the data derived from the rising part of the current-voltage curve. The slope of the Tafel plot is equal to $n_{\alpha}(1-\alpha) F / 2.3 R T$. Since this was $6.3622 \mathrm{~V} /$ decade, we obtained $n_{\alpha}(1-\alpha)$ as 0.376 . This value again indicated that the one electron transfer process was the rate determining step and the transfer coefficient $\alpha=0.624$. There was good agreement between the results from the two methods.

\subsection{Influence of SWCNT thickness, electrolyte solutions, and $\mathrm{pH}$ value}

The thickness of the SWCNT film depends on the amount of SWCNT placed onto the electrode surface, and it influences the current. When the amount of SWCNT was increased, the peak current increased, which resulted from the electrode surface area increase. The peak current reached a maximum at $20 \mu \mathrm{l}$ and then remained almost unchanged up to $25 \mu \mathrm{l}$. When the value exceeded $25 \mu \mathrm{l}$, the peak current decreased. This was due to the variation of film thickness and solidity. When the film was thin, the amount of SWCNTs on the CCE was small and the modification of electrode was not complete, and thus the peak current of CAF oxidation was small. When it was too thick, the conductivity of the film dropped, and the film no longer adhered tightly, such that some SWCNTs were removed from the electrode surface. In addition, when the amount of SWCNT increased, the background current also increased, thus, the signal/noise $(\mathrm{S} / \mathrm{N})$ ratio changed. Taking into account the stability of the film and the $\mathrm{S} / \mathrm{N}$ ratio, a $20 \mu \mathrm{L}$ SWCNT solution suspension was used for the following experiments.

Different electrolyte solutions can also influence the electrochemical behavior of CAF. In order to investigate the effect of the electrolyte $[38,39], \mathrm{CVs}$ of the SWCNT/CCE in the presence of $3.0 \times 10^{-3} \mathrm{~mol} / \mathrm{L} \mathrm{CAF}$ in $0.01 \mathrm{~mol} / \mathrm{L}$ of different electrolytes including $\mathrm{H}_{2} \mathrm{SO}_{4}, \mathrm{HNO}_{3}$, and $\mathrm{HCl}$ were 
used. The highest current response was obtained with 0.01 $\mathrm{mol} / \mathrm{L} \mathrm{H}_{2} \mathrm{SO}_{4}$ [39].

The $\mathrm{pH}$ value of the electrolyte is an important factor that affects the redox behavior of biomolecules and drugs. The peak potential and peak current of CAF are closely related to the $\mathrm{pH}$ of the electrolyte solution. For the determination of the effect of $\mathrm{pH}$ value on the SWCNT/CCE response, different $\mathrm{pH}$ values were investigated by CVs. The effect of $\mathrm{pH}$ on the $E_{\mathrm{pa}}$ and peak current $\left(I_{\mathrm{pa}}\right)$ of CAF electrooxidation on the SWCNT/CCE was examined (Fig. 5).

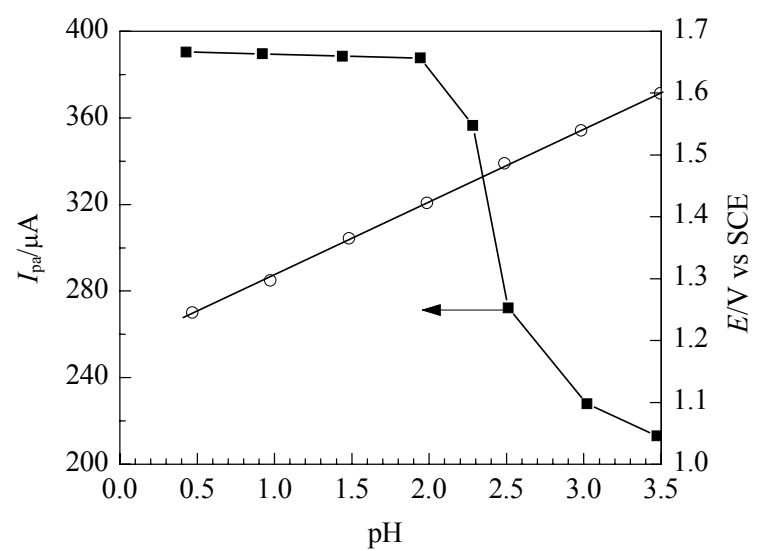

Fig. 5. Effect of $\mathrm{pH}$ on the peak potential and peak current for the electrooxidation of $3.0 \times 10^{-3} \mathrm{~mol} / \mathrm{L}$ CAF the SWCNT/CCE in $\mathrm{H}_{2} \mathrm{SO}_{4}$ solution. Volume of SWCNT was $20 \mu \mathrm{L}$.

In the $\mathrm{pH}$ range of 1.0 to 3.5 , the $E_{\mathrm{pa}}$ shifted positively with increasing $\mathrm{pH}$, and followed the linear equation $E_{\mathrm{pa}}(\mathrm{V})$ $=1.19+0.058 \mathrm{pH}\left(R^{2}=0.993\right)$. The value of $\mathrm{d} E_{\mathrm{pa}} / \mathrm{dpH}$ of 58 $\mathrm{mV} / \mathrm{pH}$ for $\mathrm{CAF}$ indicated the involvement of an equal number of protons and electrons $\left(4 \mathrm{e}^{-}, 4 \mathrm{H}^{+}\right)$in the electrooxidation reaction of CAF $[5,39,42]$. On the other hand, Fig. 5 shows that the oxidation peak current was dependent on $\mathrm{pH}$. The current signal decreased with increasing $\mathrm{pH}$ value [39]. It is evident that acidic media $(\mathrm{pH}<2)$ were the most suitable. Therefore, $0.01 \mathrm{~mol} / \mathrm{L} \mathrm{H}_{2} \mathrm{SO}_{4}$ solution and $\mathrm{pH}$ 1.7 were chosen for the subsequent experiments.

The mechanism for CAF electrooxidation (Scheme 1) $[21,37-39,42]$ involves four electrons $\left(4 \mathrm{e}^{-}\right)$and four protons $\left(4 \mathrm{H}^{+}\right)$. The first step is a $2 \mathrm{e}^{-}, 2 \mathrm{H}^{+}$oxidation of the $\mathrm{C}-8$ to $\mathrm{N}-9$ bond to give the substituted uric acid. This is followed by an immediate $2 \mathrm{e}^{-}, 2 \mathrm{H}^{+}$oxidation to the 4,5-diol analog of uric acid, which rapidly fragments.

\subsection{Evaluation of the catalytic reaction rate constant}

Chronoamperometry can be used to evaluate the catalytic reaction rate constant $\left(k_{\mathrm{cat}}\right)$ for the electrochemical oxidation reaction between $\mathrm{CAF}$ and the redox sites of the surface-confined SWCNTs [43-45]. Figure 6 shows chronoamperograms of SWCNT/CCE in $0.01 \mathrm{~mol} / \mathrm{L} \mathrm{H}_{2} \mathrm{SO}_{4}$ solution in different concentration of CAF. The transient currents decayed with time in a Cotrellian manner. The rate constant was obtained using the equation [43]:

$$
I_{\text {cat }} / I_{\mathrm{L}}=\pi^{1 / 2}\left(k_{\mathrm{cat}} c_{0} t\right)^{1 / 2}
$$

where $I_{\text {cat }}$ and $I_{\mathrm{L}}$ were the currents in the presence and absence of CAF, respectively, $k_{\text {cat }}$ is the rate constant $(\mathrm{L} /(\mathrm{mol} \cdot \mathrm{s})), c_{0}$ is the bulk concentration $(\mathrm{mol} / \mathrm{L})$ of CAF, and $t$ is the elapsed time (s). From the slope of $I_{\text {cat }} / I_{\mathrm{L}}$ versus $t^{1 / 2}$ (inset of Fig. 6 for $1.0 \times 10^{-5} \mathrm{~mol} / \mathrm{L}$ of CAF), $k_{\text {cat }}$ for the electrooxidation of CAF was calculated to be $(1.8 \pm 0.05)$ $\times 10^{4} \mathrm{~L} /(\mathrm{mol} \cdot \mathrm{s})$.

\subsection{Analytical approaches}

The analysis of the CAF solutions of different concentrations was carried out under selected analytical conditions ( $\mathrm{pH}=1.7$, amount of SWCNT suspension was $20 \mu \mathrm{l}$ ). There was a good linear relationship in the cyclic voltammetric method between the anodic peak current and the concentra-

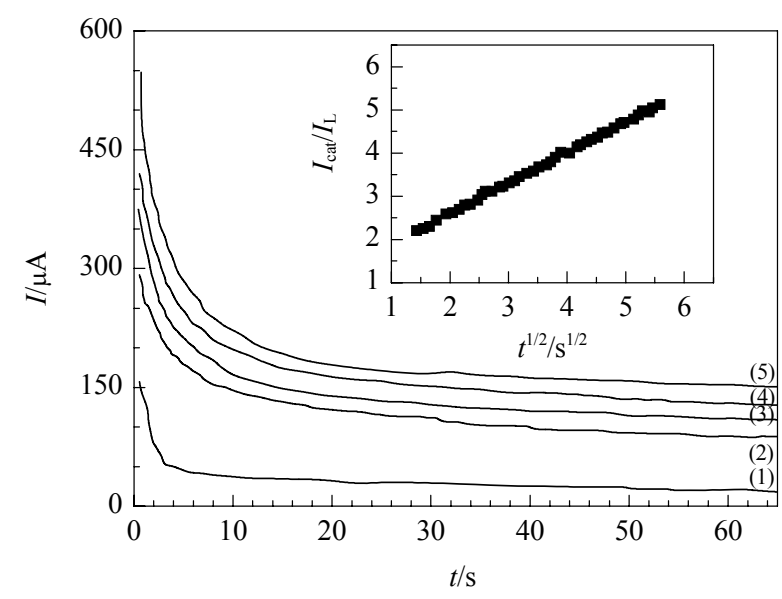

Fig. 6. Chronoamperograms of SWCNT/CCE in $0.01 \mathrm{~mol} / \mathrm{L} \mathrm{H}_{2} \mathrm{SO}_{4}$, $\mathrm{pH} 1.7$ solution containing $0 \mathrm{~mol} / \mathrm{L}(1), 5 \times 10^{-5} \mathrm{~mol} / \mathrm{L}(2), 10 \times 10^{-5}$ $\mathrm{mol} / \mathrm{L}(3), 15 \times 10^{-5} \mathrm{~mol} / \mathrm{L}(4)$, and $20 \times 10^{-5}(5) \mathrm{mol} / \mathrm{L} \mathrm{CAF}$. Plot of $I_{\text {cat }} / I_{\mathrm{L}}$ versus $t^{1 / 2}$ for $10 \times 10^{-5} \mathrm{~mol} / \mathrm{L}$ CAF (inset). Volume of SWCNT was $20 \mu 1$.

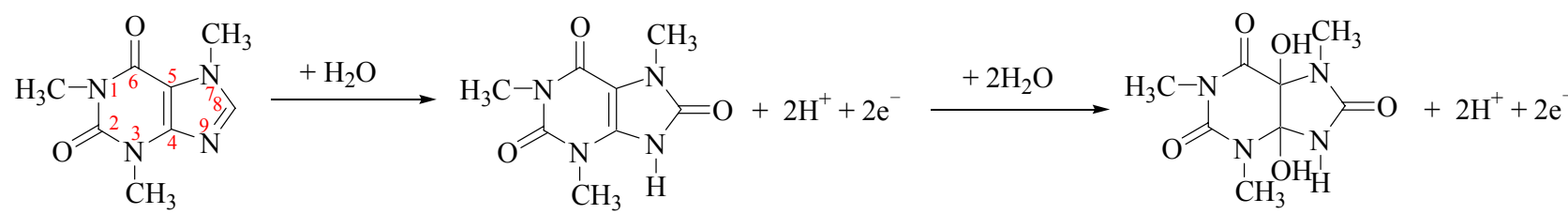

Scheme 1. Electrooxidation mechanism of CAF. 
tion for concentrations from $5.0 \times 10^{-6} \mathrm{~mol} / \mathrm{L}$ to $5.0 \times 10^{-3}$ mol/L (Fig. 7). When the CAF concentration exceeded $5.0 \times$ $10^{-3} \mathrm{~mol} / \mathrm{L}$, the curve began to deviate from the linear plot. The detection limit was estimated to be $3.1 \times 10^{-6} \mathrm{~mol} / \mathrm{L}$ $(\mathrm{S} / \mathrm{N}=3)$.

Differential pulse voltammetry (DPV) is often used to make electrochemical measurements because of its high sensitivity and low background current. In Fig. 8(a), there was a good linear relationship between $I_{\mathrm{pa}}$ and CAF concentration in the range $2.5 \times 10^{-7}-1.0 \times 10^{-7} \mathrm{~mol} / \mathrm{L}$ (inset Fig. 8) with the regression equation: $I_{\mathrm{pa}}=3.71+0.83 c_{\mathrm{CAF}}\left(R^{2}=\right.$ $0.996)$. The detection limit was $1.2 \times 10^{-7} \mathrm{~mol} / \mathrm{L}(\mathrm{S} / \mathrm{N}=3)$.

In ten successive determinations of a $5.0 \times 10^{-5} \mathrm{~mol} / \mathrm{L}$ CAF solution, the relative standard deviation (RSD) for the peak current was $3.0 \%$. When a $5.0 \times 10^{-5} \mathrm{~mol} / \mathrm{L}$ CAF solution was measured with the same electrode every several hours during one day, the RSD of the peak current was 3.2\% $(n=6)$, which showed that the electrode gave good reproducibility. After several days of repeated use, the response of the electrode was decreased only slightly. This indicated that the electrode was very stable. A comparison of the analytical performance of the present modified electrode with some other relevant modified electrodes for CAF determination is shown in Table 1. Compared with the other electrochemical methods, the present method has many advantages for the determination of CAF. Furthermore, the preparation of the electrode was simple, the modified electrode was quite stable, and it had good sensitivity and gave good reproducibility.

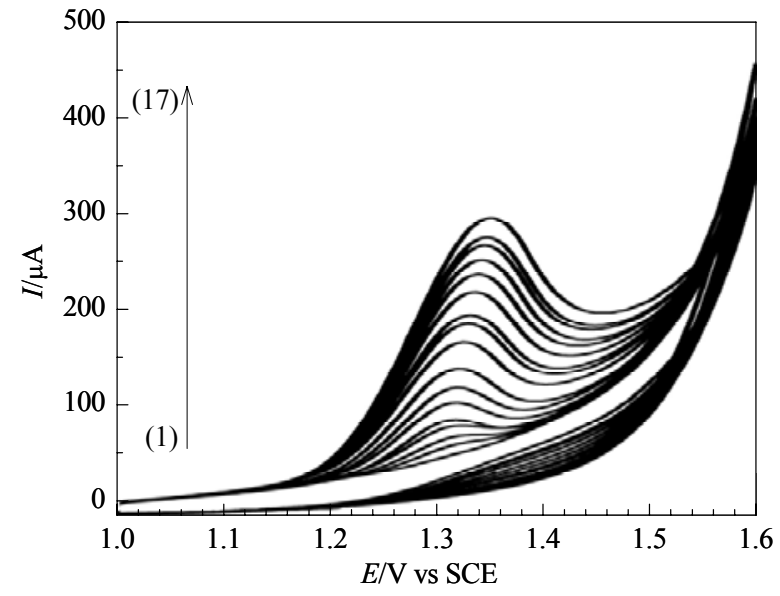

Fig. 7. CVs of CAF at concentrations of $0(1), 20 \times 10^{-6}(2), 50 \times$ $10^{-6}(3), 100 \times 10^{-6}(4), 150 \times 10^{-6}(5), 200 \times 10^{-6}(6), 300 \times 10^{-6}(7)$, $400 \times 10^{-6}(8), 600 \times 10^{-6}(9), 800 \times 10^{-6}(10), 900 \times 10^{-6}(11), 1100 \times$ $10^{-6}(12), 1300 \times 10^{-6}(13), 1700 \times 10^{-6}(14), 1900 \times 10^{-6}(15), 2000 \times$ $10^{-6}(16), 2200 \times 10^{-6}(17) \mathrm{mol} / \mathrm{L}$ in $0.01 \mathrm{~mol} / \mathrm{L} \mathrm{H}_{2} \mathrm{SO}_{4}$, pH 1.7 solution at the SWCNT/CCS. Scan rate $50 \mathrm{mV} / \mathrm{s}$, volume of SWCNT casted $20 \mu 1$.

\subsection{Interference study}

Possible interference of the detection of CAF with the SWCNT modified CCE was investigated by the addition of various ions to the $0.01 \mathrm{~mol} / \mathrm{L}, \mathrm{pH} 1.7 \mathrm{H}_{2} \mathrm{SO}_{4}$ solution with $5 \times 10^{-5} \mathrm{~mol} / \mathrm{L} \mathrm{CAF}$. Common ions such as $\mathrm{Na}^{+}, \mathrm{K}^{+}, \mathrm{Cu}^{2+}$, $\mathrm{Cl}^{-}, \mathrm{NO}_{3}{ }^{-}$, and $\mathrm{CO}_{3}{ }^{2-}$ did not show interference on $\mathrm{CAF}$ detection even when these were present in over 500-fold

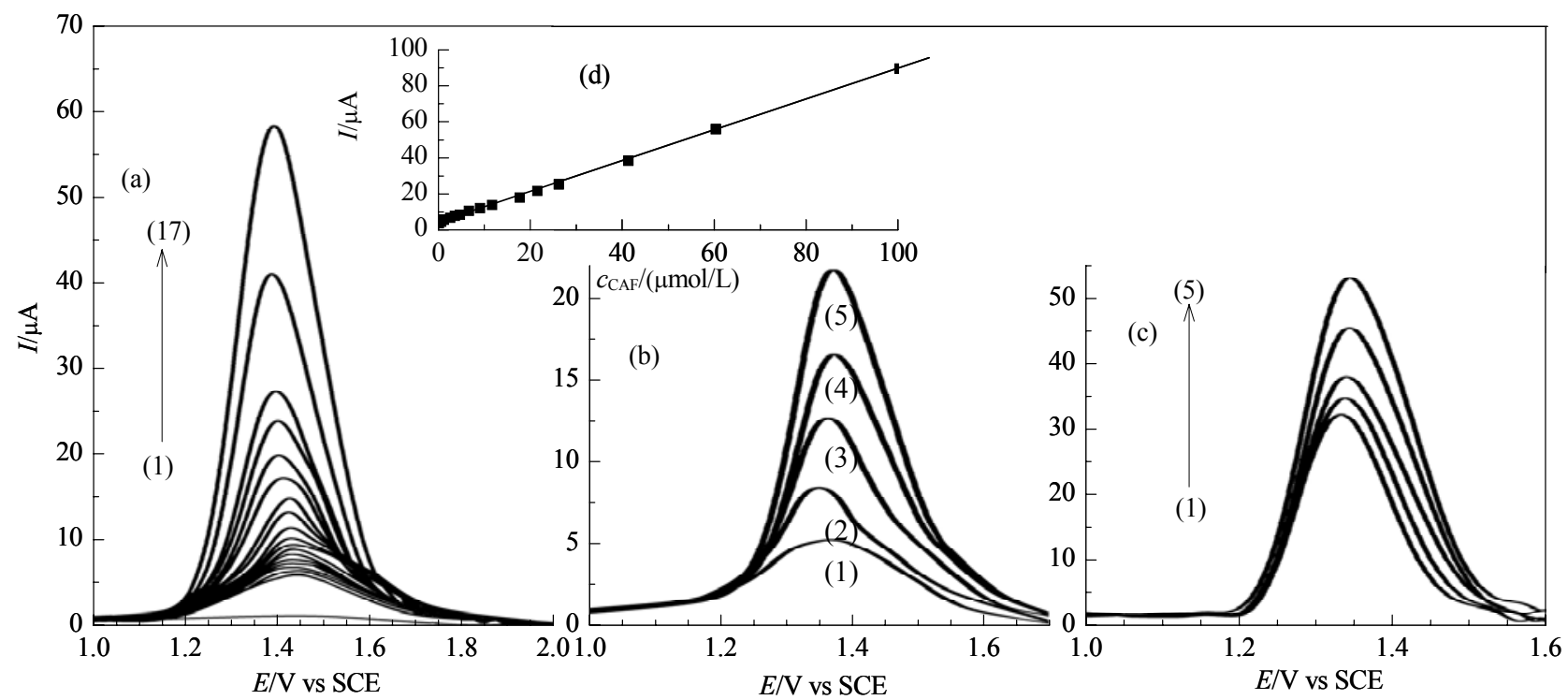

Fig. 8. DPVs of CAF at concentrations of $0.25 \times 10^{-6} \mathrm{~mol} / \mathrm{L}(1), 0.32 \times 10^{-6} \mathrm{~mol} / \mathrm{L}(2), 0.42 \times 10^{-6} \mathrm{~mol} / \mathrm{L}(3), 0.57 \times 10^{-6} \mathrm{~mol} / \mathrm{L}(4), 0.87 \times 10^{-6}$ $\mathrm{mol} / \mathrm{L}(5), 1.67 \times 10^{-6} \mathrm{~mol} / \mathrm{L}(6), 1.97 \times 10^{-6} \mathrm{~mol} / \mathrm{L}(7), 2.47 \times 10^{-6} \mathrm{~mol} / \mathrm{L}(8), 3.37 \times 10^{-6} \mathrm{~mol} / \mathrm{L}(9), 5.02 \times 10^{-6} \mathrm{~mol} / \mathrm{L}(10), 7.17 \times 10^{-6} \mathrm{~mol} / \mathrm{L}(11)$, $12.17 \times 10^{-6} \mathrm{~mol} / \mathrm{L}(12), 18.17 \times 10^{-6} \mathrm{~mol} / \mathrm{L}(13), 22.17 \times 10^{-6} \mathrm{~mol} / \mathrm{L}(14), 26.67 \times 10^{-6} \mathrm{~mol} / \mathrm{L}(15), 41.47 \times 10^{-6} \mathrm{~mol} / \mathrm{L}(16)$ and $60.17 \times 10^{-6} \mathrm{~mol} / \mathrm{L}$ (17) in $0.01 \mathrm{~mol} / \mathrm{L} \mathrm{H}_{2} \mathrm{SO}_{4}, \mathrm{pH} 1.7$ solution (a). DPVs of cola (b) and tea (c) samples results obtained after the addition of various amounts (0 (1), 10 (2), 20 (3), 35 (4), and 50 (5) $\mu \mathrm{mol} / \mathrm{L}$ for cola and 0 (1), 10 (2), 40 (3), 100 (4), and 200 (5) $\mu \mathrm{mol} / \mathrm{L}$ for tea) of standard CAF to samples (Pulse amplitude: $70 \mathrm{mV}$, pulse width: $50 \mathrm{~ms}$, volume of SWCNT casted $20 \mu \mathrm{L}$ ). Plot of peak currents vs CAF concentration (d). 
Table 1 Comparison of the analytical performance of the present modified electrode with some other modified electrode for CAF determination

\begin{tabular}{|c|c|c|c|c|}
\hline \multirow[b]{2}{*}{ Modified electrode } & \multicolumn{4}{|c|}{ Dynamic liner Detection } \\
\hline & Method & $\begin{array}{c}\text { range } \\
(\mu \mathrm{mol} / \mathrm{L})\end{array}$ & $\begin{array}{c}\text { limit } \\
(\mu \mathrm{mol} / \mathrm{L})\end{array}$ & Ref. \\
\hline Nafion/MWNTs & DPV & $0.6-400$ & 0.23 & 1 \\
\hline BDDE & DPV & $0.5-83.0$ & 0.035 & 5 \\
\hline Nafion/GCE & DPV & $0.995-10.6$ & 0.798 & 20 \\
\hline BDDE/Nafion $®$ & DPV & $0.2-120$ & 0.1 & 23 \\
\hline MIP-CPE & DPV & $0.06-25$ & 0.015 & 23 \\
\hline MWNTs-Nafion/GCE & DPV & $2.945-377.0$ & 0.513 & 24 \\
\hline BDDE & DPV & $9.7-110$ & 7.0 & 27 \\
\hline PST/Nafion/GCE & DPV & $0.3-100$ & 0.1 & 28 \\
\hline Nafion-Gr/GCE & DPV & $0.4-40$ & 0.12 & 36 \\
\hline DNA-CNTs/CPE & DPV & $0.512-61.7$ & 0.35 & 46 \\
\hline $\mathrm{Pt} / \mathrm{CNTs} / \mathrm{GCE}$ & DPV & $10-100$ & 0.2 & 47 \\
\hline SWCNT/CCE & DPV & $0.25-100$ & 0.12 & This work \\
\hline
\end{tabular}

excess concentrations. To test interference in biological and other real samples, 250-fold excess concentrations of ascorbic acid, dopamine, uric acid, and vitamin $\mathrm{B}_{6}$, and 150-fold concentrations of codeine, morphine, and acetaminophen were shown to give no interference on the response current of CAF (signal change $<5 \%$ ), which showed that the present method has excellent selectivity towards CAF.

\subsection{Application using practical samples}

CAF is the main and active ingredient in coffee, tea, and cola nuts. Its concentration in CAF containing food samples is determined for quality control purposes. To simulate this, a known amount of the food sample solution was added to $10 \mathrm{ml}$ of $0.01 \mathrm{~mol} / \mathrm{L}$ and $\mathrm{pH} 1.7 \mathrm{H}_{2} \mathrm{SO}_{4}$ solution, and their DPVs were recorded. First, the applicability of the present method was evaluated by analyzing CAF-free mineral water samples. The results obtained are shown in Table 2.

It can be seen from the Table that the added and measured concentrations were generally in good agreement. The present method was also applied to the analysis of cola and tea samples. The DPVs of cola (Zam Zam Cola) and tea (Ahmad tea) samples are presented in Figs. 8(b) and 8(c), respectively. The average value of four repeated measurements of the oxidation peak current was used to determine the concentration of CAF in the cola and tea samples to minimize possible effects due to the presence of other components in the samples. The amount of CAF in cola was found to be $35 \pm 3.6 \mathrm{mg} / \mathrm{L}$ and in tea, it was $3.01 \pm 0.19 \%$ $(\mathrm{m} / \mathrm{m})$, which were in good agreement with Alizadeh's results [23].

\section{Conclusions}

Table 2 Determination of CAF in mineral water (CAF-free samples)

\begin{tabular}{lcccc}
\hline Sample $^{\mathrm{a}}$ & $\begin{array}{c}\text { Spiked } \\
(\mu \mathrm{mol} / \mathrm{L})\end{array}$ & $\begin{array}{c}\text { Found } \\
(\mu \mathrm{mol} / \mathrm{L})\end{array}$ & $\begin{array}{c}\text { Recovery } \\
(\%)\end{array}$ & $\begin{array}{c}\mathrm{RSD}^{\mathrm{b}} \\
(\%)\end{array}$ \\
\hline Zam Zam mineral water 1 & 50.00 & 49.25 & 98.5 & 3.7 \\
Zam Zam mineral water 1 & 50.00 & 49.60 & 99.2 & 3.5 \\
Vata mineral water 1 & 50.00 & 49.55 & 99.1 & 3.5 \\
Vata mineral water 2 & 50.00 & 50.05 & 100.1 & 3.6 \\
\hline
\end{tabular}

${ }^{\text {a }}$ Some available commercial mineral water brands in Iran.

${ }^{\mathrm{b}}$ Number of Sample assayed $=5$.

A simple, fast, and reproducible procedure was used for the fabrication of a single-walled carbon nanotube modified carbon-ceramic electrode (SWCNT/CCE). The use of the reversible couple $\left[\mathrm{Fe}(\mathrm{CN})_{6}\right]^{3-/ 4-}$ as a probe electrochemical reaction showed that the SWCNT/CCE has good chemical and electrochemical stability when it was used for the electrocatalytic oxidation of CAF. CAF was oxidized at the SWCNT/CCE and produced an anodic peak at $1.38 \mathrm{~V}$ (vs $\mathrm{SCE}$ ) in $0.01 \mathrm{~mol} / \mathrm{L}, \mathrm{pH} 1.7 \mathrm{H}_{2} \mathrm{SO}_{4}$. The peak was suitable for the determination of the concentration of CAF. The peak currents in two different voltammetric methods were linear in concentration over a large concentration range. CAF concentration can be measured without any interference in the presence of a large excess of some important biological and addictive compounds such as codeine, morphine, and acetaminophen. This procedure was applied to the determination of CAF in some food samples.

\section{Acknowledgments}

The authors gratefully acknowledge the research council of Azarbaijan University of Tarbiat Moallem for financial support.

\section{References}

1 Yang S, Yang R, Li G, Qu L, Li J, Yu L. J Electroanal Chem, 2010, 639: 77

2 Ashihara H, Suzuki T. Front Biosci, 2004, 9:1864

3 Rieg T, Steigele H, Schnermann J, Richter K, Osswald H, Vallon V. J Pharmacol Exp Ther, 2005, 313: 403

4 Soloveychik V, Bin-Nun A, Ionchev A, Sriram S, Meadow W. J Perinatol, 2009, 29: 205

5 Lourencao B C, Medeiros R A, Rocha-Filho R C, Mazo L H, Fatibello-Filho O. Talanta, 2009, 78: 748

6 Sawynok J. Drugs, 1995, 49: 37

7 Baranska M, Proniewicz L M. Vib Spectrosc, 2008, 48: 153

8 Wei Y F, Wang D Y, Yan H T. Spectrosc Spect Anal, 2001, 21: 534

9 Wang H, Chen L, Xu Y, Zeng Q, Zhang X, Zhao Q, Ding L. LWT-Food Sci Technol, 2011, 44: 1490

10 Soponar F, Mot A C, Sarbu C. Chromatographia, 2009, 69: 151 
11 Wang A, Sun J, Feng H J, Gao S, He Z G. Chromatographia, 2008, 67: 281

12 Verenitch S S, Mazumder A. Anal Bioanal Chem, 2008, 391: 2635

13 Arinobu T, Hattori H, Kumazawa T, Lee X P, Mizutani Y, Katase T, Kojima S, Omori T, Kaneko R, Ishii A, Seno H. Forensic Toxicol, 2009, 27: 1

14 Aranda M, Morlock G. J Chromatogr Sci, 2007, 45: 251

15 Emre D, Ozaltin N. J Chromatogr B, 2007, 847: 126

16 Amini A, Barclay V, Rundlof T, Jonsson S, Karlsson A, Arvidsson T. Chromatographia, 2006, 63: 143

17 Sadik O A, Land W H, Wang J. Electroanalysis, 2003, 15: 1149

18 Zen J M, Ting Y S, Shih Y. Analyst, 1998, 123: 1145

19 Akyilmaz E, Turemis M. Electrochim Acta, 2010, 55: 5195

20 Brunetti B, Desimoni E, Casati P. Electroanalysis, 2007, 9: 385

21 Spãtaru N, Sarada B V, Tryk D A, Fujishima A. Electroanalysis, 2002, 14: 721

22 Martínez-Huitle C A, Suely Fernandes N, Ferro S, De Battisti A, Quiroz M A. Diamond Relat Mater, 2010, 19: 1188

23 Alizadeh T, Ganjali M R, Zare M, Norouzi P. Electrochim Acta, 2010, 55: 1568

24 Zhang J, Wang L P, Guo W, Peng X D, Li M, Yuan Z B. Int J Electrochem Sci, 2011, 6: 997

25 Riahi S, Faridbod F, Ganjali M R. Sens Lett, 2009, 7: 42

26 Katsu T, Tsunamoto Y, Hanioka N, Komagoe K, Masuda K, Narimatsu S. Anal Chim Acta, 2008, 620: 50

27 Lourenção B C, Medeiros R A, Rocha-Filho R C, Fatibello-Filho O. Electroanalysis, 2010, 22: 1717

28 Guo S, Zhu Q, Yang B, Wang J, Ye B. Food Chem, 2011, 129: 1311
29 Meyyappan M. Carbon Nanotubes Science and Applications. Florida: CRC Press LLC, 2005. 171

30 Valcárcel M, Simonet B M, Cárdenas S, Súarez B. Anal Bioanal Chem, 2005, 382: 1783

31 Trojanowicz M. TrAC Trends Anal Chem, 2006, 25: 480

32 Merkoçi A. Microchim Acta, 2006, 152: 157

33 Tsionsky M, Gun G, Glezer V, Lev O. Anal Chem, 1994, 66: 1747

34 Lev O, Wu Z, Bharathi S, Glezer V, Modestov A, Gun J, Rabinovich L, Sampath S. Chem Mater, 1997, 9: 2354

35 Bard A J, Faulkner L R. Electrochemical Methods: Fundamentals and Applications. New York: Wiley, 2001

36 Habibi B, Jahanbakhshi M, Pournaghi-Azar M H. Microchim Acta, 2011, 172: 147

37 Dryhurst G, Hansen B H. J Electroanal Chem, 1971, 30: 407

38 Telo J P, Vieira A J S C. J Chem Soc, Perkin Trans, 1997, 29: 1755

39 Sun J Y, Huang K J, Wei S Y, Wu Z W, Ren F P. Colloids Surf $B, 2011,84: 421$

40 Zhang Z, Wang E. Electrochemical Principles and Methods. Beijing: Science Press, 2000. 242

41 Mersal G A M. Food Anal Methods, 2012, 5: 520

42 Goyal R N, Bishnoi S, Agrawal B. J Electroanal Chem, 2011, 655: 97

43 Galus Z. Fundamentals of Electrochemical Analysis. New York: Ellis Hornood, 1976. 10

44 Ardakani M M, Karami P E, Rahimi P, Zare H R, Naeimi H. Electrochim Acta, 2007, 52: 6118

45 Laviron E. J Electroanal Chem, 1979, 101: 19

46 Ly S Y, Lee C H, Jung Y S. Neuromol Med, 2009, 11: 20

47 Wei Y, Zhang L, Shao C, Li C. Chem Anal (Warsaw), 2009, 54: 607 